\title{
O DESENVOLVIMENTO DO GEOTURISMO NOS GEOSSÍTIOS CÂNIONS DOS APERTADOS, PICO DO TOTORÓ E MINA BREJUÍ, MUNICÍPIO DE CURRAIS NOVOS, RN.
}

\author{
Sebastiana Guedes Bezerra ${ }^{1}$; Valdeci Pereira da Silva Filho ${ }^{1}$, Wagner Araújo Oliveira ${ }^{1}$, \\ Marcos Antônio Leite do Nascimento ${ }^{2}$
}

1- Universidade Federal do Rio Grande do Norte, UFRN, Campus Universitário Lagoa Nova, CEP 59078-97, Natal, RN - anaguedesberra@hotmail.com, valdecifilho30@hotmail.com, wagnercnrn@hotmail.com

2- Universidade Federal do Rio Grande do Norte, Departamento de Geologia da UFRN, RN, Brasil - marcos@geologia.ufrn.br

RESUMO:A geodiversidade ganha destaque de forma crescente no âmbito social e acadêmico, prova disso é o número de publicações nessa temática, bem como a valorização que a sociedade atribui atualmente para esse aspecto. Assim sendo, o presente trabalho tem por objetivo propor estratégias para o desenvolvimento do geoturismo nos geossítios Cânions dos Apertados, Pico do Totoró e Mina Brejuí inseridos na proposta do Geoparque Seridó, que estão localizados no município de Currais Novos/RN. Os processos metodológicos consistem na revisão da literatura, visita in loco e hierarquização dos geossítios a partir da metodologia do Ministério do Turismo. Pode-se destacar como resultados a possibilidade de inserção da comunidade no geoturismo, a possibilidade de realização de diferentes ações (minicursos, palestras, oficinas) que visem à sensibilização, valorização e interpretação ambiental das comunidades locais sobre o patrimônio geológico; efetivação de estratégias promocionais acerca dos geossítios e melhorias na infraestrutura turística dos lugares. Portanto, considera-se que o geoturismo pode vir a ser um importante fator de desenvolvimento socioeconômico para o município de Currais Novos/RN, bem como para a conservação do patrimônio geológico dos geossítios.

\section{Palavras-chave: DESENVOLVIMENTO. GEOTURISMO. CURRAIS NOVOS. GEOPARQUE SERIDÓ}

ABSTRACT: DEVELOPMENT OF GEOTOURISM IN CÂNIONS DOS APERTADOS, PICO DO TOTORÓ AND MINA BREJUÍ GEOSITES, MUNICIPALITY OF CURRAIS NOVOS, RN. Geodiversity is increasingly gaining a place on the social and academic scene, as the great number of publications on this theme attest, along with the value currently given to this subject by society at large. Thus, the objective of the present study is to propose strategies for the development of geotourism at the geosites of: Cânion dos Apertados, Pico do Totoró, and the Mina Brejuí, components of the Seridó Geopark, located in the county of Currais Novos/RN. The research methodology consists of bibliographic and documental research, field work and the ranking of geosites using the Ministry of Tourism's Ranking Methodology. Featured results highlight the possibility of including the local communities in geotourism, as well as structuring different activities (mini-courses, lectures, workshops, among others) that aim to sensitize, give value to and interpret the environment for the local communities about their geological heritage; put strategies into place that promote geosites and improve touristic infrastructure of these places. Therefore, we found that geotourism can become an important factor in the socioeconomic development of the county of Currais Novos/RN, as well as in the conservation of geological heritage of the geosites.

Keywords: DEVELOPMENT. GEOTOURISM. CURRAIS NOVOS. SERIDÓ GEOPARK

\section{INTRODUÇÃO}

Entende-se que a atividade turística é subdividida em diversos segmentos, e que constantemente surgem novos segmentos, um deles é o geoturismo, que por sua pouca idade é ainda incipiente de estudos e apresenta controversas em sua definição, no entanto percebe-se que por meio das pesquisas de autores como Moreira, Ruchkys, Nascimento, Mantesso-Neto, entre outros que é crescente o número de estudos que suprem essa necessidade, contribuindo para enriquecimento teórico/prático do segmento.

Nesse sentido, considera-se que geoturismo é:

[...] um segmento da atividade turística que tem o patrimônio geológico como seu principal atrativo e busca sua proteção por meio da conservação de seus recursos e da sensibilização do turista, utilizando, para isto, a interpretação deste patrimônio tornando-o acessível ao público leigo, além de promover a sua divulgação e o desenvolvimento das Ciências da Terra. (RUCKHYS, 2007, p. 23 apud BENTO; RODRIGUES, 2010, p. 58).
Conservar o patrimônio geológico configura-se como um dos objetivos do geoturismo, que tenta proporcionar ao visitante a interpretação ambiental em relação aos recursos geológicos e assim contribuir para sua valorização e conservação.

Alguns autores afirmam que o geoturismo vem na verdade complementar a lacuna deixada pelo ecoturismo no tocante a contemplação do patrimônio geológico em suas definições, nesse sentido Moreira (2010, p. 5) diz que "[...] por mais que as definições de Ecoturismo contenham o patrimônio natural, nenhuma delas abrange a geodiversidade como parte do produto turístico, citando muitas vezes unicamente a biodiversidade." O geoturismo é portando um segmento diferente do ecoturismo, tendo em vista que no destaque como atrativo turístico são os aspectos geológicos, já no segundo são os relacionados ao meio biótico - fauna e flora. (NASCIMENTO; RUCHKYS; MANTESSO-NETO, 2007). Todavia, ambos visam a conservação de elementos da natureza.

Pode-se dizer que no Brasil o segmento geoturístico conta com um considerável potencial de crescimento, haja vista que algumas cidades 
atualmente tiram proveito desses recursos, tais como a cidade do Rio de Janeiro/RJ com o Pão de Açúcar, Natal/RN com o Morro do Careca, Aracati/CE com as Falésias da Praia de Canoa Quebrada, entre outras. Esses são apenas alguns casos de locais que tem o patrimônio geológico como um dos principais atrativos turísticos.

Além disso, existem pelo país inúmeras localidades que apresentam pontos de interesse turístico e geológico, porém ainda não são usados e valorados de maneira correta, pois se fossem planejados de forma adequada poderiam contribuir para o desenvolvimento local. Nessa linha de pensamento Moreira (2010, p. 8) afirma que:

[...] o Geoturismo pode chegar a assumir um grau de importância estratégica para o futuro do desenvolvimento turístico do Brasil, como fator de desenvolvimento social, educação e valorização do potencial das comunidades envolvidas, além do marketing a nível nacional e internacional. [...]

Sendo assim, percebe-se que o segmento geoturístico apresenta-se como sendo uma forma de contribuir para o desenvolvimento e para a conservação dos recursos naturais dos lugares onde é implantado.

Diante desse contexto, vale destacar a importância do planejamento para desenvolvimento da atividade turística, sendo assim, faz-se necessário entender o que vem a ser o planejamento turístico e sua importância para o desenvolvimento dos segmentos turístico no âmbito regional.

Para tanto, o planejamento é um elemento que consiste na adoção de ações que almejam promover o desenvolvimento socioeconômico de uma determinada localidade.

Para ser eficaz, o planejamento deve ser um processo dinâmico e permanente que incorpore o mais próximo possível a complexa realidade que pretende organizar. (DIAS, 2008. p. 88). É interessante que se englobe nesse processo todos os atores (setor público e privado/comunidade local), pois dessa forma pretende-se atingir os anseios de todos envolvidos na cadeia produtiva.

Hall (2004), afirma que o planejamento pode ser considerado como um tipo de tomada de decisões e preparação de políticas, onde trabalha com decisões interdependentes ou ordenadamente relacionadas e não isoladamente.

No caso do turismo, o planejamento deve ser uma ferramenta primordial, pois esse processo deve levar em consideração os aspectos sociais, ambientais e econômicos, tendo em vista ser caracterizada como uma atividade consumidora de recursos naturais. Pois para que seja alcançado o objetivo final, faz-se necessário que o planejamento aborde os aspectos de forma equitativa buscando a maximização dos benefícios e a minimização dos efeitos nocivos que poderão ser gerados ou intensificados pela atividade turística.

Levando-se em considerações o atual cenário do turismo no Brasil, onde há um destaque para as políticas de interiorização e regionalização do turismo, a Região Seridó apresenta-se inserida nesse contexto, haja vista o seu potencial para desenvolvimento do turismo, ampliando a oferta de segmento almejando atingir diversos públicos, como também promover o desenvolvimento socioeconômica por meio de geração de renda, a conservação dos aspectos naturais e a valorização dos elementos histórico-culturais.

Nesse sentido, como forma de ordenamento e planejamento do território foi pensando uma proposta de geoparque, onde essa prevê a conservação e valoração dos aspectos geológicos por meio do desenvolvimento do geoturismo.

O Geoparque é um território com limites definidos que apresenta geossítios de especial valor científico/educativo/uso turístico. Além de sua importância para preservação da memória geológica (geoconservação), a presença de valores ecológicos, arqueológicos, históricos e culturais inseridos num processo de desenvolvimento sustentável que fomenta projetos geoturísticos, educacionais e de valorização do patrimônio cultural local, dessa maneira agrega valor à proposta de criação do geoparque.

Nesse contexto, o Seridó apresenta um dos mais completos e ricos patrimônios geológicos encontrados no Nordeste do Brasil, o qual é decorrente de inúmeros processos naturais a que esta região foi submetida ao longo do tempo Geológico. Tendo em vista o caráter excepcional deste patrimônio geológico, associado ao aspecto cultural da região, considera-se que a área proposta atende as necessidades para criação do Geoparque Seridó.

Vale salientar que na região existe o Pólo e Conselho de Turismo, fomentado pelo Serviço Brasileiro de Apoio às Micro e Pequenas Empresas (Sebrae), e Secretaria de Turismo do Rio Grande do Norte entre outras organizações, que criaram em 2004 o Projeto Roteiro Seridó e está integrado ao Programa Territórios da Cidadania do Governo Federal.

A região também já apresenta painéis geoturísticos do Projeto Monumentos Geológicos do Rio Grande do Norte, criado pelo Instituto de Desenvolvimento Sustentável do Meio Ambiente do 
Rio Grande do Norte (Idema) para divulgar o patrimônio geológico potiguar. O referido projeto conta com a sinalização de 16 monumentos, tendo na região Seridó 3 painéis já instalados (Mina Brejuí, Pluton de Acari e Pegmatito de Parelhas).

A área da Proposta Geoparque Seridó situa-se no semiárido nordestino, região centro-sul do Estado do Rio Grande do Norte, envolvendo totalmente os territórios dos municípios de Bodó, Cerro Corá, Lagoa Nova, Currais Novos, São Vicente, Tenente Laurentino Cruz, Florânia, Caicó, São José do Seridó, Cruzeta, Acari, Carnaúba dos Dantas, Jardim do Seridó e Parelhas. Estes municípios fazem parte da mesorregião Central Potiguar e englobam partes das microrregiões Serra de Santana, Seridó Oriental e Seridó Ocidental.

Diante do que foi discutido, o presente trabalho tem como objetivo geral, propor estratégias para o desenvolvimento do geoturismo nos geossítios Cânions dos Apertados, Pico do Totoró e Mina Brejuí inseridos na proposta do Geoparque Seridó que estão localizados no município de Currais Novos/RN. E como específicos: a) caracterizar geologicamente e turisticamente os geossítios; b) hierarquizar turisticamente os geossítios; c) apontar estratégias para o desenvolvimento do geoturismo dos geossítios.

\section{MATÉRIAS E MÉTODOS}

Os elementos da pesquisa são os geossítios que compõe a proposta do Geoparque Seridó, entre os quais serão analisados geossítios Cânion dos Apertados, Pico do Totoró e a Mina Brejuí localizados no Município de Currais Novos/RN.

Em meio a esse cenário, existem diversos pontos no município que configuram-se como aspecto potencial para o desenvolvimento do geoturismo como é o caso Pico do Totoró, Cânions dos Apertados e a Mina Brejuí, inseridos na Proposta do Geoparque Seridó, a seguir a figura 1 retrata todo o território contemplando na Proposta.

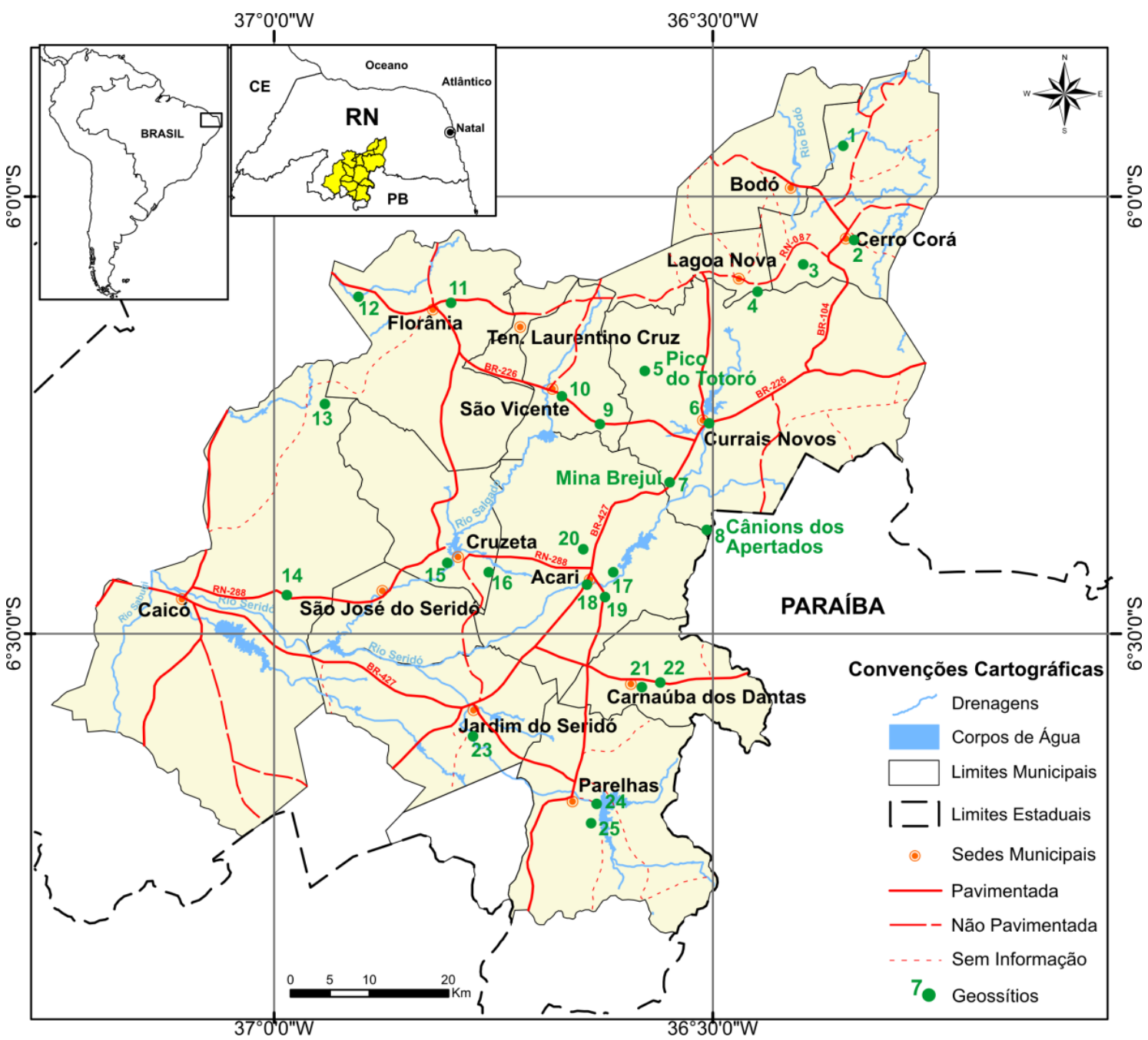

Figura 1 - Mapa com a localização dos geossítios do Projeto Geoparque Seridó. 
No que se refere aos objetivos da pesquisa a mesma classifica-se como exploratória, pois de acordo com Severino (2007, p. 123) "a pesquisa exploratória busca levantar informações sobre um determinado objeto, delimitando assim um campo de trabalho, mapeando as condições de manifestação desse objeto".

Além disso, a pesquisa se deu através de análise documental, que segundo Dencker (1998), são materiais que ainda não receberam tratamento analítico ou que podem ser elaboradas, como a Proposta do Geoparque Seridó. Utilizou-se também a pesquisa bibliográfica, que segundo Medeiros (2008, p. 39), caracteriza-se "pelo levantamento e leitura de livros e revistas de relevante interesse para a pesquisa que será realizada".

A pesquisa se caracteriza como descritiva, que "são estudos bem estruturados e planejados que exigem um conhecimento profundo do problema estudado por parte do pesquisador e compreendem uma série de técnicas de levantamento." (DENCKER, 1998, p. 130)

Também ocorreu a pesquisa de campo, momento em que realizou-se o inventário dos atrativos em espaços naturais dos três geossítios do município analisado, por meio do formulário de inventariação do Ministério do Turismo (MTur) (2006). Na oportunidade, ocorreu também a captura de imagens.

A hierarquização dos geossítios ocorreu utilizando a aplicação da metodologia do Ministério do Turismo (2007), onde foram analisados sete parâmetros com seus respectivos valores, tais como: 0 - inexistente, 1 - baixo, 2 - médio e 3 - alto. No final é feita a somatória são avaliados os parâmetros como representatividade que fundamentam-se na singularidade ou raridade do atrativo, bem como o estado de conservação da paisagem.

\section{RESULTADOS}

\subsection{Caracterização turística e geológica dos} geossítios

\subsubsection{Cânions dos Apertados}

O Geossítio denominado Cânions dos Apertados situa-se na Fazenda Aba da Serra, distante $10 \mathrm{~km}$ da cidade de Currais Novos. Como acesso até o geossítio tem-se inicialmente a BR 426, em seguida o percurso é feito por estrada de chão batido.

Turisticamente o local dispõe do Rio Picuí, formações rochosas, fauna e flora, sendo que o destaque fica por conta das águas do Rio Picuí que estão encrustadas entre os cânions rochosos, atribuindo assim um considerável nível de beleza cênica ao local, como mostra a figura 2. Prova disso, é o fato do lugar ter sido eleito em um concurso como a 7 a Maravilhas do Rio Grande do Norte.

O ponto alto da visitação turística acontece no período chuvoso da região, sendo que o rio fica cheio, possibilitando aos visitantes desfrutar do banho em suas águas, além de possibilitar a contemplação da paisagem e realização de trilhas.

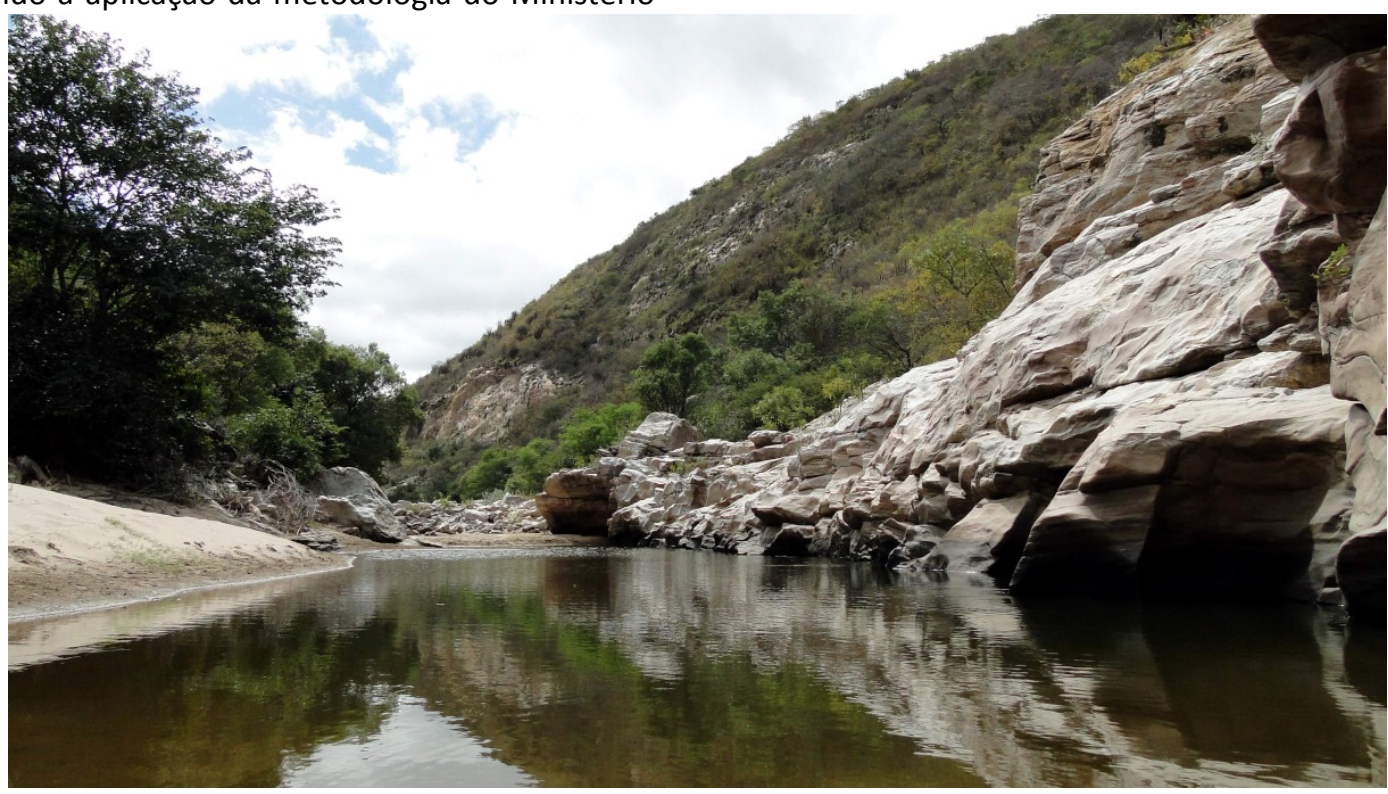

Figura 2 - Cânion dos Apertados formado em quartzitos e cortado pelo Rio Picuí. 
Como aspectos geológicos pode-se destacar que no geossítio ocorre quartzito constituído principalmente por quartzo e eventualmente muscovita, biotita e minerais opacos. Exibe aspecto compacto de cor esbranquiçada, tendendo a tons de creme, com um brilho significativo (quando da presença de minerais micáceos) e alguns pontos de minerais escuros. Apresenta uma foliação tectônica bem evidenciada, caracterizada pelo estiramento dos minerais, por dobras e fraturas de direção NE de alto ângulo (75-80). Possui granulometria fina a média, além de conter mobilizados de quartzo. Por vezes se observam estratificações cruzadas. Este quartzito faz parte da Formação Equador. Ocorrem ainda diques de pegmatitos que cortam o quartzito, formados por K-feldspato, quartzo, biotita e turmalina, os dois últimos em pequenas quantidades. (PROPOSTA GEOPARQUE SERIDÓ, 2010)

\subsubsection{Pico do Totoró}

O Geossítio Pico do Totoró situa-se no Distrito Totoró, há aproximadamente $10 \mathrm{~km}$ do centro de Currais Novos, tem como principal acesso uma estrada de chão batido. Nesse local foi onde ocorreu o primeiro povoamento da cidade, por esse motivo é dotado de importância histórico cultural para o município.

$\mathrm{O}$ atrativo geoturístico de maior destaque nesse geossítio é o Pico do Totoró, como é possível observar na figura 3. A visita ao atrativo consiste principalmente na subida por meio de uma trilha até chegar o topo, ao longo do percurso existem mirantes onde é possível contemplar a paisagem do local, permitindo também visualizar algumas cidades da região.
Outros aspectos encontrados no geossítio Pico do Totoró dão destaque para geoformas, como: Pedra do Caju (formação rochosa que remete ao formato de um caju), Pedra do Navio (rocha que quando o Açude Totoró está cheio tem semelhança com um navio em navegação), Pedra do Sino (geoforma que emite som similar a um sino de bronze quando impactada), Lagoa do Santo (local onde foram encontrados fósseis de mamíferos da megafauna e Pedra Furada (rocha que servia de abrigo aos antepassados).

Geologicamente nesse local predominam rochas de natureza granítica, de cor cinza a rósea contendo minerais grandes (conhecidos como fenocristais). Além de K-feldspato ocorre ainda plagioclásio e quartzo, bem como biotita, anfibólio, titanita, minerais opacos, allanita, epidoto, apatita e zircão. Associados aos granitos, porém em menores proporções, ocorrem dioritos e gabros equigranulares de textura fina a média, de cor verde escura a preta, compostos por piroxênios, anfibólios, biotita, além de plagioclásio e quartzo. Em menores quantidades são identificados ainda Kfeldspato, epidoto, titanita, olivina, além de minerais opacos, allanita, apatita e zircão. Esse conjunto de rochas ocorre separado, porém muitas vezes é possível constatar evidências de processos de misturas (coexistência) de magmas, através da presença de termos híbridos e a captura de cristais porfiríticos (feldspatos). Este granito está incluído na Suíte Intrusiva Itaporanga, sendo conhecido como Pluton Totoró, com idade estimada em 580 milhões de anos (PROPOSTA GEOPARQUE SERIDÓ, 2010).

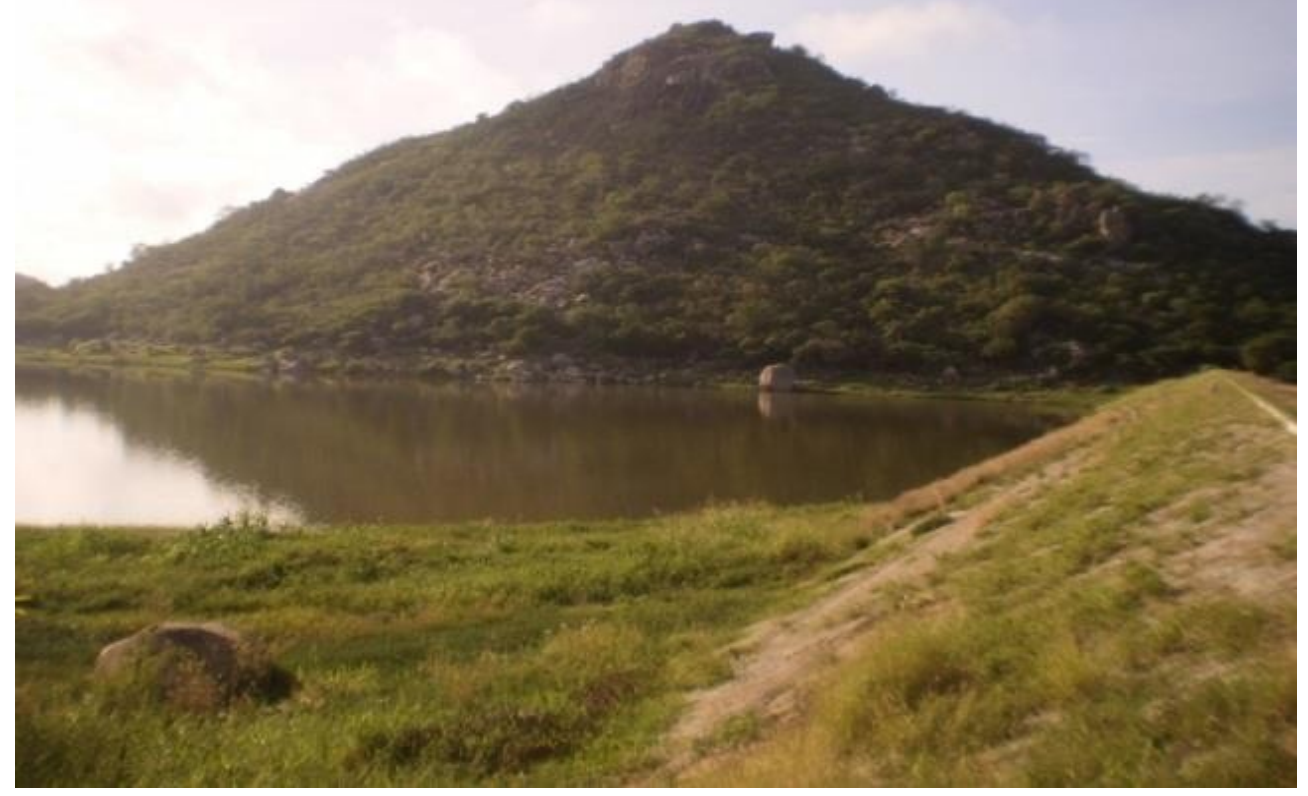

Figura 3 - Pico do Totoró formado por granitos ao lado do açude homônimo. 


\subsubsection{Mina Brejuí}

O geossítio Mina Brejuí localiza-se no município de Currais Novos/RN, o acesso ao local se dá pela BR 226, nas instalações da mina é possível visitar o Memorial Tomaz Salustino (ver figura 4), construído em homenagem ao fundador e proprietário da Mineração Tomaz Salustino S/A.

Nesse memorial é retratada a história do Desembargador Tomaz Salustino e sua família, podese encontrar um acervo de objetos, artefatos e fotos, ressaltando acontecimentos importantes e o fato da mineração ter exercido considerável relevância econômica para a cidade de Currais Novos/RN na época da II Guerra Mundial, por esse motivo o local é dotado de considerável importância cultural para a cidade e para o estado.

Outro ponto que pode ser visitado é o Museu Mineral Mario Moacyr Porto, no museu existe considerável variedade de minerais e rochas, com destaque para a sheelita, o principal mineral extraído da mina. As visitas ao Memorial Tomaz Salustino e ao Museu Mineral Mario Moacyr Porto acontecem com auxílio de um guia de turismo.

Ainda como ponto de visita do atrativo destaquese os túneis e galerias da Mina Brejuí (ver figura 5), estes tem uma extensão total de aproximadamente 300 metros, na qual é composta por diversos andares no subsolo onde acontece a extração mineral. A visita se dá por meio do principal túnel da Mina, onde o visitante pode visualizar a maneira como é realizada a extração, além disso, com auxílio do mineralight (equipamento usado no estudo da fluorescência dos minerais) pode-se observar o mineral sheelita.

Geologicamente o geossítio é caracterizado com diferentes tipos de rochas. É comum identificar paragnaisses de cor cinza, constituídos de quartzo, feldspato e biotita, além de epidoto, microclina, muscovita, minerais opacos, tremolita/actinolita, por vezes destacando níveis centimétrico de calciossilicática composta principalmente de epidoto, titanita, quartzo, plagioclásio, apatita, hornblenda, malaquita, molibdenita e tremolita/actinolita. É principalmente nas rochas calcissilicáticas que ocorrem a mineralização de tungstênio, devido a presença de scheelita. Exibe forte foliação marcada pelas orientações de biotitas e nível calciossilicático, com granulometria fina (paragnaisse) a média (calciossilicática). As condições metamórficas destas rochas atingiram a fácies anfibolito superior evidenciada pela formação de microclina, plagioclásio e anfibólio substituindo a biotita. Além dessas rochas ocorrem ainda, sob a forma de camadas, mármores de cor cinza clara a branca e predominantemente monominerálica carbonática. A rocha é homogênea e compacta, formada essencialmente por calcita, tendo eventualmente minerais opacos, tremolita e mica branca, com granulometria média (PROPOSTA GEOPARQUE SERIDÓ, 2010).

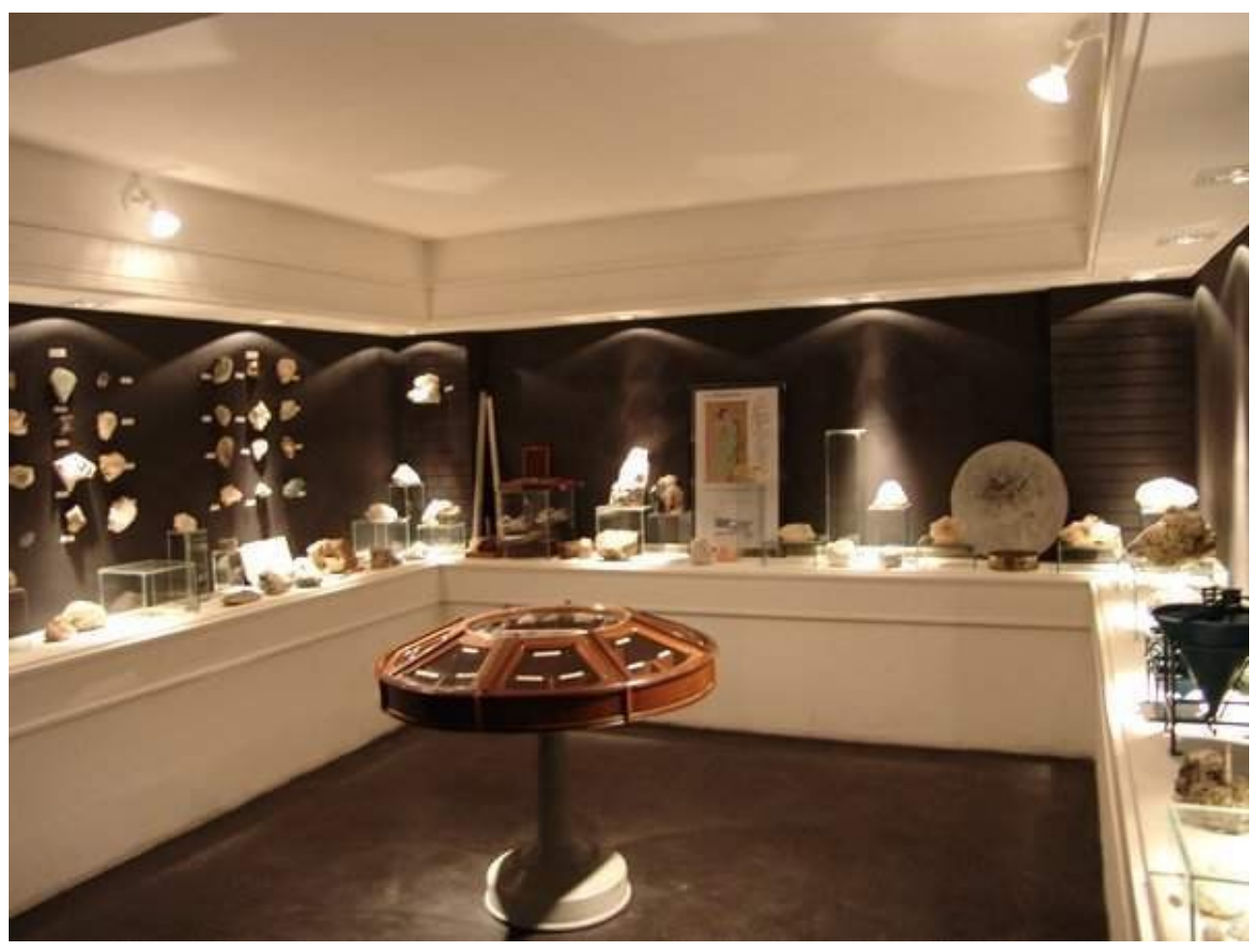

Figura 4 - Visão de uma das salas do Museu Mineral Mário Porto na Mina Brejuí. 


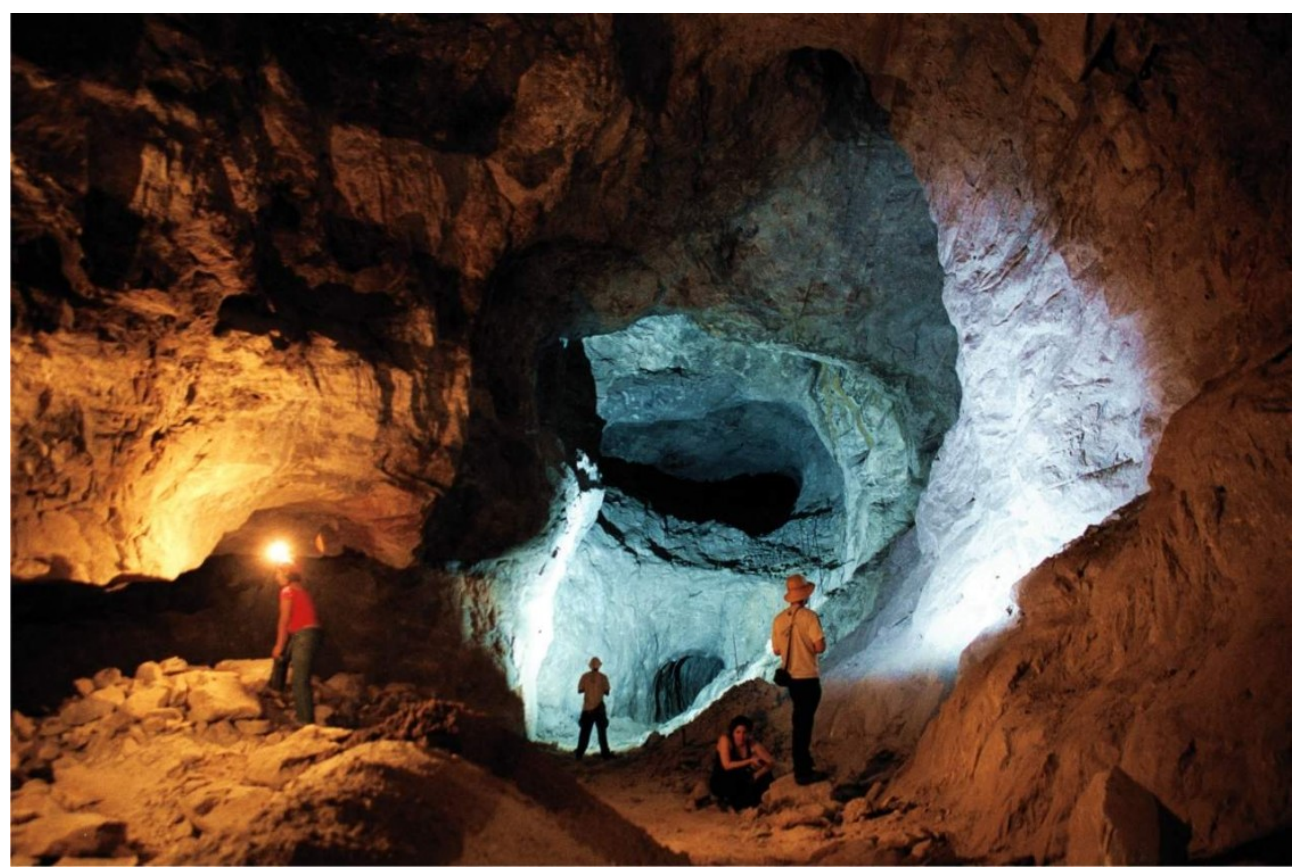

Figura 5 - Um dos salões visitados dentro da Mina Brejuí.

\subsection{Hierarquização dos Geossítios}

Hierarquizar atrativos turísticos consiste em quantificar o seu valor turístico de acordo com parâmetros estabelecidos previamente. Para o geossítios usou-se o modelo utilizado pela Organização Mundial do Turismo (OMT) e pelo Centro de Interamericano de Capacitação Turística (CICATUR).

Os parâmetros e os resultados da quantificação estão expressos no quadro 1.

A partir desses resultados, é possível observar que $o$ item representatividade foi $o$ que teve destaque entre todos os geossítios, de forma que a Mina Brejuí e os Cânions dos Apertados lideram esse quesito, sendo que apresentam singularidade ou raridade do atrativo, levando-se em consideração a Região Seridó.

O Quadro 1 ainda mostra que o Geossítio Mina Brejuí se destaca dos demais com pontuação elevada (total de 23) principalmente nos itens potencial de atratividade, representatividade, infraestrutura e acesso. O Geossítio Pico do Totoró foi o que recebeu menor nota total (14) principalmente devido ao grau de uso atual, representatividade e infraestrutura. Já com relação ao Geossítio Cânions dos Apertados tem baixo potencial de atratividade, grau de uso atual, apoio local e comunitário, acesso e infraestrutura, o que te oferece um resultado não tão expressivo.

Todavia, um aspecto negativo, aponta-se a infraestrutura dos geossítios, com exceção da Mina Brejuí que dispõe de uma infraestrutura turística suficiente que atende a demanda atual. Em quanto que o Pico do Totoró e os Cânions dos Apertados receberem o menor valor possível.

Quadro 1 - Hierarquização dos geossítios.

\begin{tabular}{|c|c|c|c|}
\hline \multicolumn{4}{|c|}{ GEOSSÍTIOS } \\
\hline CRITÉRIOS & $\begin{array}{l}\text { Pico do } \\
\text { Totoró }\end{array}$ & Mina Brejuí & $\begin{array}{l}\text { Cânions } \\
\text { dos } \\
\text { Apertados }\end{array}$ \\
\hline Potencial de atratividade & 4 & 6 & 2 \\
\hline Grau de uso atual & 1 & 2 & 1 \\
\hline Representatividade & 4 & 6 & 6 \\
\hline Apoio local e comunitário & 3 & 3 & 1 \\
\hline $\begin{array}{l}\text { Estado de conservação da } \\
\text { paisagem circundante }\end{array}$ & 2 & 1 & 2 \\
\hline Infraestrutura & 0 & 2 & 0 \\
\hline Acesso & 2 & 3 & 1 \\
\hline Total & 14 & 23 & 15 \\
\hline
\end{tabular}

Fonte: Bezerra et al., 2014.

\subsection{Propostas de estratégias para o} desenvolvimento do geoturismo

A partir da caracterização turística e geológica e hierarquização dos geossítios, notou-se que os Cânions dos Apertados, o Pico do Totoró e a Mina Brejuí dispõem de características que possibilitam o desenvolvimento do geoturismo. Para tanto, propõe-se a adoção de algumas estratégias:

- Melhorias na infraestrutura turística dos lugares;

- Elaboração e efetivação de estratégias promocionais acerca dos geossítios;

- A realização de diferentes ações (minicursos, palestras, oficinas, entre outros) que visem à sensibilização, valorização e interpretação ambiental das comunidades locais sobre o patrimônio geológico; 
- Inserção dos geossítios em roteiros turísticos comercializados;

- Inserir o geoturismo no Plano de Desenvolvimento Integrado do Turismo Sustentável (Pdits).

\section{CONCLUSÕES}

Em harmonia com as premissas da sustentabilidade, o geoturismo tem a possibilidade de trazer considerável quantidade de aspectos positivos para as localidades onde é desenvolvido, de modo que a comunidade local seja a principal beneficiada, por meio da inserção no mercado de trabalho e obtenção de renda. Além disso, promover a conservação do patrimônio geológico e minimização de danos, permitindo que as futuras gerações utilizem-o.

Contudo, é fundamental que essa atividade aconteça de maneira planejada, caso isso não ocorra, certamente a destinação será impactada negativamente. Nesse contexto, o presente trabalho tem a intenção de alertar para essa questão nos geossítios Pico do Totoró, Mina Brejuí e Cânions dos Apertados, além de apontar estratégias que contribuirão para o desenvolvimento dessa atividade nesses locais.

Desse modo, identifica-se alternativas para o desenvolvimento do turismo na Região Seridó, haja vista a necessidade de outras atividades econômicas sejam melhor trabalhadas, bem como, o notável potencial existente nos recursos naturais para o uso turístico.

\section{REFERÊNCIAS}

Bento L. C. M., Rodrigues S. C. 2010. O geoturismo como instrumento em prol da divulgação, valorização e conservação do patrimônio natural abiótico - uma reflexão teórica. Turismo e Paisagens Cársticas, Campinas/SP, v. 3, n. 2, p. 55-65.

Dencker A. F. M. 1998. Métodos e técnicas de pesquisa em turismo. 6. ed. São Paulo: Futura, 286p.

Dias R. 2008. Aspectos básicos sobre planejamento. In: Planejamento do turismo: politica e desenvolvimento do turismo no Brasil. São Paulo: Atlas, p. 87-111.

2008. Planejamento do turismo em nível local. In: Planejamento do turismo: política e desenvolvimento do turismo no Brasil. São Paulo: Atlas, p. 152-179.

Hall C. M. 2004. Política e planejamento turístico: o imperativo sustentável. In:. Planejamento turístico: política, processos e relacionamentos. 2. ed. São Paulo: Contexto, p. 17-37.

Medeiros J. B. 2008. Redação científica: a prática de fichamentos, resumos, resenhas. 10. ed. São Paulo: Atlas, 321p.

Moreira J. C. 2010. Geoturismo: uma abordagem históricoconceitual. Turismo e Paisagens Cársticas, Campinas/SP, v. 3, n. 1, p. 5-10.

Nascimento M. A. L., Ruchkys U. A., Mantesso-Neto V. 2007. Geoturismo: um novo segmento do turismo no Brasil. Global Tourism, [s/l], v. 3, n. 2, 24p.

Contribuição ao II Simpósio Brasileiro de Patrimônio Geológico I Workshop Brasileiro de Patrimônio Geológico Construído 24 a 28 de setembro de 2013, Ouro Preto, MG 